\title{
Early-Life Environmental Factors Can Increase the Risk of Allergic Rhinitis
}

\author{
Doo Hee Han (iD · Chae-Seo Rhee (i) \\ Department of Otorhinolaryngology-Head and Neck Surgery, Seoul National University Hospital, \\ Seoul National University College of Medicine, Seoul, Korea
}

Different prevalence rates of allergic rhinitis (AR), ranging from $2.9 \%$ to $54.1 \%$, have been reported across various regions and age groups [1]. Moreover, the prevalence of AR has markedly increased in some affluent Asian countries. According to the Korea National Health and Nutrition Examination Survey 2010, which included allergy testing for the general population, the nationwide prevalence of AR was $16.2 \%$ [2]. It varies according to region and year of study, because AR is a multi-factorial disease caused by the interaction between genetic and environmental factors.

Although the etiology and risk factors are not completely understood, various genetic factors are responsible for AR. Family history of AR, sex, autoimmune diseases, human leukocyte antigen, and single nucleotide polymorphisms have been suggested as related factors through genetic or epidemiological studies. However, since it is currently difficult to modify these genetic factors, some researchers have focused on early-life environmental factors that could be amenable to intervention. Early-life environmental factors include pattern of delivery, breastfeeding, the number of siblings and living conditions, child's infection history, including that of the mother during pregnancy, use of antibiotics, and other medications.

Numerous studies have investigated the association between the mode of delivery and allergic diseases, but have failed to reach a unanimous conclusion. However, the cesarean section seems to be associated with an increased risk of allergic diseases. Infants born by cesarean section lack contact with the bifidogenic bacteria in their mother's vagina, which is thought to affect immune modulation and subsequent development of AR. Moreover, breastfeeding is associated with a decreased risk of allergic diseases, although studies on its influence have yielded conflicting results. A Swedish birth cohort study showed that exclusive breastfeeding in early infancy reduced the risk for eczema (odds ratio [OR], 0.78; 95\% confidence interval [CI], 0.63 to 0.96 ) and onset of allergic march [3]. Another study in the United States showed that prolonged breastfeeding in African American subjects reduced the risk of AR (adjusted OR [aOR], 0.8; 95\% CI, 0.6 to 0.9 ) at age 3 years [4]. The results from the Allergic Rhinitis Cohort Study for kids (ARCO-kids study) also showed that long-term breastfeeding is strongly associated with a decreased risk of AR in Korean children [5]. The possible protective mechanism conferred by breastfeeding is explained by its beneficial effects of lung development, as well as the presence of immune modulating factors in breast milk [6]. The number of siblings has been found to have protective effects in several earlier studies, including the previously mentioned Cincinnati study (aOR, 0.4; 95\% CI, 0.2 to 0.8 ) [4]. The previous history of infection is a protective factor according to the hygiene hypothesis and our recent study showed that a previous history of pneumonia reduced the risk for $\mathrm{AR}(\mathrm{OR}, 0.39 ; 95 \% \mathrm{CI}, 0.19$ to 0.82$)$ [7]. A German study on bacterial infection in early life and the exposure of house dust mite (HDM) allergens in bed showed a contrasting effect of early endotoxin and HDM exposure for HDM sensitization [8]. HDM exposure increased the risk of mite sensitization at 5 years (aOR, 1.30; 95\% CI, 1.11 to 1.53), while endotoxin exposure was inversely associated with HDM sensitization (aOR, 0.73; 95\% CI, 0.57 to 0.95 ), which means bacterial exposure during early life may act as a protective factor against allergic diseases in childhood. However, another study with a birth cohort suggested that exposure to antibiotics is a potential risk factor in the development of allergic diseases [9]. In utero exposure to antibiotics was associated with an increased risk of asthma (adjusted hazard ratio [aHR], 1.68; 95\% CI, 1.51 to 1.87), eczema (aHR, 1.17; 95\% CI, 1.06 to 1.29) and AR (aHR, 1.56; $95 \% \mathrm{CI}, 1.22$ to 2.01 ). Antibiotic use in early life disrupts the infant gut microbiota and decreases their overall diversity, po-

Copyright (C) 2019 by Korean Society of Otorhinolaryngology-Head and Neck Surgery.

This is an open-access article distributed under the terms of the Creative Commons Attribution Non-Commercial License (http://creativecommons.org/licenses/by-nc/4.0)

which permits unrestricted non-commercial use, distribution, and reproduction in any medium, provided the original work is properly cited. 
tentially leading to the development of allergic diseases. Therefore, bacterial exposure or the history of infection during early childhood should not be considered by itself, but in conjunction with the use of antibiotics to assess the exact effect on the development of AR. Interestingly, a recent cohort study found that acetaminophen, a widely used drug, increased the risk of AR by more than three times if used before the age of 3 [10].

Modification of genetic factors is difficult, but modification of the early-life environmental factors, including breastfeeding, mode of delivery, and living conditions, can prevent the development of allergic diseases including AR; it may also potentially reduce the increasing medical and socioeconomic burden associated with allergic diseases.

\section{CONFLICT OF INTEREST}

No potential conflict of interest relevant to this article was reported.

\section{ORCID}

Doo Hee Han https://orcid.org/0000-0003-3367-1495

Chae-Seo Rhee https://orcid.org/0000-0002-1361-8585

\section{REFERENCES}

1. Katelaris CH, Lee BW, Potter PC, Maspero JF, Cingi C, Lopatin A, et al. Prevalence and diversity of allergic rhinitis in regions of the world beyond Europe and North America. Clin Exp Allergy. 2012 Feb;42(2):186-207.
2. Rhee CS, Wee JH,Ahn JC, LeeWH,Tan KL,Ahn S, et al. Prevalence, risk factors and comorbidities of allergic rhinitis in South Korea:The Fifth Korea National Health and Nutrition Examination Survey. Am J Rhinol Allergy. 2014 Mar-Apr;28(2):e107-14.

3. Kull I, Bohme M,Wahlgren CF, Nordvall L, Pershagen G, Wickman M. Breast-feeding reduces the risk for childhood eczema. J Allergy Clin Immunol. 2005 Sep;116(3):657-61.

4. Codispoti CD, Levin L, LeMasters GK, Ryan P, Reponen T, Villareal $\mathrm{M}$, et al. Breast-feeding, aeroallergen sensitization, and environmental exposures during infancy are determinants of childhood allergic rhinitis. J Allergy Clin Immunol. 2010 May;125(5):1054-60.e1.

5. Han DH, Shin JM, An S, Kim JS, Kim DY, Moon S, et al. Long-term breastfeeding in the prevention of allergic rhinitis: Allergic Rhinitis Cohort Study for Kids (ARCO-Kids Study). Clin Exp Otorhinolaryngol. 2019 Aug;12(3):301-7.

6. Oddy WH.A review of the effects of breastfeeding on respiratory infections, atopy, and childhood asthma. J Asthma. 2004 Sep;41(6): 605-21.

7. Han DH, Ahn JC, Mun SJ, Park SK, Oh SY, Rhee CS. Novel risk factors for allergic rhinitis in Korean elementary school children: ARCO-kids phase II in a community. Allergy Asthma Immunol Res. 2015 May;7(3):234-40.

8. Illi S, Weber J, Zutavern A, Genuneit J, Schierl R, Strunz-Lehner C, et al. Perinatal influences on the development of asthma and atopy in childhood. Ann Allergy Asthma Immunol. 2014 Feb;112(2):1329.e1.

9. McKeever TM, Lewis SA, Smith C, Hubbard R. The importance of prenatal exposures on the development of allergic disease: a birth cohort study using the West Midlands General Practice Database. Am J Respir Crit Care Med. 2002 Sep;166(6):827-32.

10. Amberbir A, Medhin G, Hanlon C, Britton J, Davey G, Venn A. Effects of early life paracetamol use on the incidence of allergic disease and sensitization: 5 year follow-up of an Ethiopian birth cohort. PLoS One. 2014 Apr;9(4):e93869. 